ISSN: 0514-7336

DOI: http://dx.doi.org/10.14201/zephyrus201576183193

\title{
EROS/CUPIDO EN UN SANTUARIO DE LA ANTIGUA CARMO (CARMONA, SEVILLA). ESTUDIO ARQUEOLÓGICO E ICONOGRÁFICO DE UN ENTALLE ROMANO
}

\section{Eros/Cupid from a cave shrine in the ancient Carmo (Carmona, Sevilla). Archaeological and iconographical analysis of a Roman gemstone}

\author{
María Limón Belén* y Juan Manuel Román RodríGuez** \\ * Grupo de Investigación HUM-156 (PAIDI). Dpto. de Filología Griega y Latina. Facultad de Filología. C/ Palos de \\ la Frontera, s/n.41004 Sevilla.Correo-e:mlimon@us.es \\ ** Grupo de Investigación HUM-650 (PAIDI). Servicio de Arqueología del Ayto. de Carmona. Cl San Ildefonso, 2. \\ 41410 Carmona. Correo-e: juanmarroman@hotmail.com
}

Recepción:10/06/2015; Revisión: 6/07/2015; Aceptación: 5/09/2015

BIBLID [0514-7336 (2015) LXXVI, julio-diciembre; 183-193]

\begin{abstract}
RESUMEN: Este artículo tiene por objeto el estudio de un entalle romano procedente de un santuario rupestre descubierto en Carmona (Sevilla). Fue tallado en cornalina y contiene la imagen de un joven alado sosteniendo con ambas manos una antorcha, que podemos identificar con Eros/Cupido. Abordamos el análisis de este ejemplar excepcional de la glíptica romana basándonos, en primer lugar, en su clasificación tipológica. A continuación, estudiamos la iconografía de Eros/Cupido a través de las referencias literarias que a él se hacen en los textos clásicos, de su papel en la mitología clásica y de su representación en el arte antiguo, centrándonos, sobre todo, en la figura del Eros antorchario. Finalmente ofrecemos una interpretación del significado del objeto a partir de los datos que aporta el contexto arqueológico, que también proporciona un terminus ante quem de tiempos de Vespasiano para fechar la pieza. El entalle, así como otros objetos encontrados junto a él, se interpretan como posibles ofrendas realizadas durante las ceremonias que precedieron al fin de la actividad del santuario.

Palabras clave: Baetica; glíptica; mitología clásica; mundus muliebris; ofrenda.
\end{abstract}

Aвstract: The aim of this paper is to study a Roman intaglio from a cave shrine discovered in Carmona (Sevilla). It is carved in carnelian and contains the image of a winged young man holding a torch with both hands that can be identified as Eros/Cupid. Firstly, the analysis of this exceptional specimen based on its typological classification is undertaken. After that, the iconography of Eros/Cupid through the Classical texts, his role in Classical mythology and its representation in Ancient art is studied with a focus on Eros the torchbearer. Finally, an interpretation of the object based on the data provided by the archaeological context is offered. The archaeological context allows the intaglio to be dated before Vespasian times. The gem and other objects found in the same context are interpreted as possible offerings preceding the end of the activity of the sanctuary.

Key words: Baetica; ancient intaglios; classical mythology; mundus muliebris; offering.

(C) Universidad de Salamanca

Zephyrus, LXXVI, julio-diciembre 2015, 183-193 


\section{El entalle y su contexto arqueológico}

Una intervención arqueológica preventiva realizada por J. M. Román en el casco antiguo de Carmona (Sevilla) entre 1999 y 2000 sacó a la luz un complejo rupestre compuesto por tres estancias, comunicadas entre sí pero con entradas independientes, excavadas en el escarpe rocoso que bordea la ciudad por el s (Fig. 1). El estudio de la excavación concluyó que estas cámaras formaron parte de un santuario que pudo estar consagrado a un Mercurio de ascendencia prerromana (Baratta, 2011: 129), asimilado con el dios romano del comercio ${ }^{1}$, probablemente el primer complejo cultual dedicado a esta divinidad de que se tiene constancia arqueológica en la Península Ibérica.

Para su interpretación, los investigadores (Belén et al., 2014a) se han basado en las prácticas rituales documentadas in situ y en el hallazgo de una terracota masculina cuya iconografía apunta claramente a los modelos clásicos que representan a Hermes/ Mercurio, pero con rasgos, sobre todo faciales, que recuerdan a terracotas fenicio-púnicas (Belén et al., 2014b). El complejo cultual estuvo en uso hasta época flavia, clausurándose en tiempos de Vespasiano o algo después. Hacia mediados del s. II d. C., había quedado sepultado bajo potentes depósitos de escombros que nivelaron la ladera y cambiaron para siempre la topografía del lugar.

La intervención arqueológica permitió comprobar que la construcción del complejo se acometió en dos fases. No se pudo precisar cuándo se hizo y se inauguró el primer edificio, dotado de una única sala -D-, que se usó hasta mediados del s. I a. C., aproximadamente. Hacia esas fechas se añadieron otras dos habitaciones $-\mathrm{A}$ y $\mathrm{C}-\mathrm{y}$ se construyó un muro de fachada que daba monumentalidad a la puerta de acceso a la dependencia más antigua. El mismo muro permitió ampliar la sala A, la más pequeña de las tres -3,20 x 2,20 m-, hacia el exterior, resultando así una habitación semihipogea (Fig. 2).

Sobre la superficie de esta sala A (Fig. 3, n. ${ }^{\circ} 2$ ) se hallaron diversos materiales que se abandonaron in

1 En acuñaciones de la ceca de Carmo de las últimas décadas del s. II a. C. Mercurio aparece caracterizado con atributos vegetales poco comunes en el dios romano, lo que lleva a pensar en un proceso de asimilación de un culto local anterior. Algunos numísmatas van más allá y equiparan al dios de estas monedas con el Mercurio africano (Rodríguez Casanova, 1999).

(C) Universidad de Salamanca situ o se depositaron de forma intencional antes de clausurar el local, entre otros, 4 monedas acuñadas durante los mandatos de Tiberio y Claudio, 2 vasos pequeños, uno de los cuales permanecía de pie sobre el suelo con un fragmento cerámico a modo de tapadera y, junto a ellos, dos grupos de remaches de hierro alineados en dobles hileras y un aplique circular de bronce. Próximas a este conjunto se hallaron, además, tres piezas cilíndricas de hueso con una perforación, fragmentos de una o más piezas similares de tamańo algo mayor y varios útiles óseos asociados al mundus muliebris ${ }^{2}$ (Fig. 3, n. $\left.{ }^{\text {os }} 2-3\right)^{3}$.

Parece que, al menos parte de estos objetos, fueron depositados de forma intencional como ofrenda en un gesto ritual de clausura y abandono del local, acompañado también de sacrificios de animales. Creemos que las dobles hileras de 5 remaches debieron adornar los laterales de un pequeño cofre o caja de madera a la que pertenecería también el disco de bronce con decoración de círculos concéntricos. Con el mecanismo de articulación de su tapa podrían estar relacionadas las piezas de hueso perforadas, bien documentadas como bisagras, de baúles y muebles ${ }^{4}$. La caja pudo contener los objetos óseos antes citados y las monedas, al menos la que se halló junto a los remaches, y la gema que estudiaremos a continuación. No se encontró anillo alguno ni otro tipo de engarce que pudiera haber contenido el entalle. Su perfecto estado de

2 Una aguja de coser, tres alfileres para recoger y sujetar el cabello, una espátula y una cucharilla para cosméticos. Sobre el empleo del acus crinalis en el arreglo del peinado femenino, $c f$. Jiménez Melero, M.: El arreglo del cabello femenino en época romana. Evidencias arqueológicas en la Bética occidental, tesis doctoral presentada en 2011 en la Univ. Cádiz, Cádiz, pp. 190-192 (http://hdl.handle. net/10498/15846; acceso 12-10-2014). Sobre el uso de perfumes y cosméticos en el mundo romano $c f$. Balsdon, 1962 o Stewart, 2007.

3 Para un conocimiento más detallado del contexto arqueológico remitimos a la obra citada de Belén et al., $2014 a$.

4 Feugère y Prévot (2008: 239) desestiman el uso de bisagras de hueso en cajas de pequeño tamaño, para cuya fabricación, según la documentación arqueológica que manejan, se utilizaban piezas iguales pero talladas en madera. Sin embargo, en este caso, el tamaño de las bisagras -de 1,54-1,56 cm de longitud las tres pequeñas y $2,85 \mathrm{~cm}$ una de las mayores- nos lleva a pensar que podrían tener relación con la articulación de la tapa de cierre de la caja que contenía los objetos hallados junto a sus restos. 
conservación tampoco ofrece pistas sobre su uso, por lo que no es posible precisar si fue utilizado como joya, como sello, como amuleto o como parte de la decoración de la propia caja, aunque esta última opción nos parece menos probable.

\section{Descripción y estudio de la pieza}

La gema que nos ocupa fue tallada en cornalina, una variedad de calcedonia, mineral de la familia de los cuarzos. Esta piedra semipreciosa ofrece una gama de tonos que van desde el rojo al amarillo dorado, pasando por el naranja (Spier, 1992: 5). Es más apreciada cuanto más translúcida y cuando su color tiende hacia el rojoanaranjado, como en este caso (Giraud, 1988: 21, fig. 2). Ya

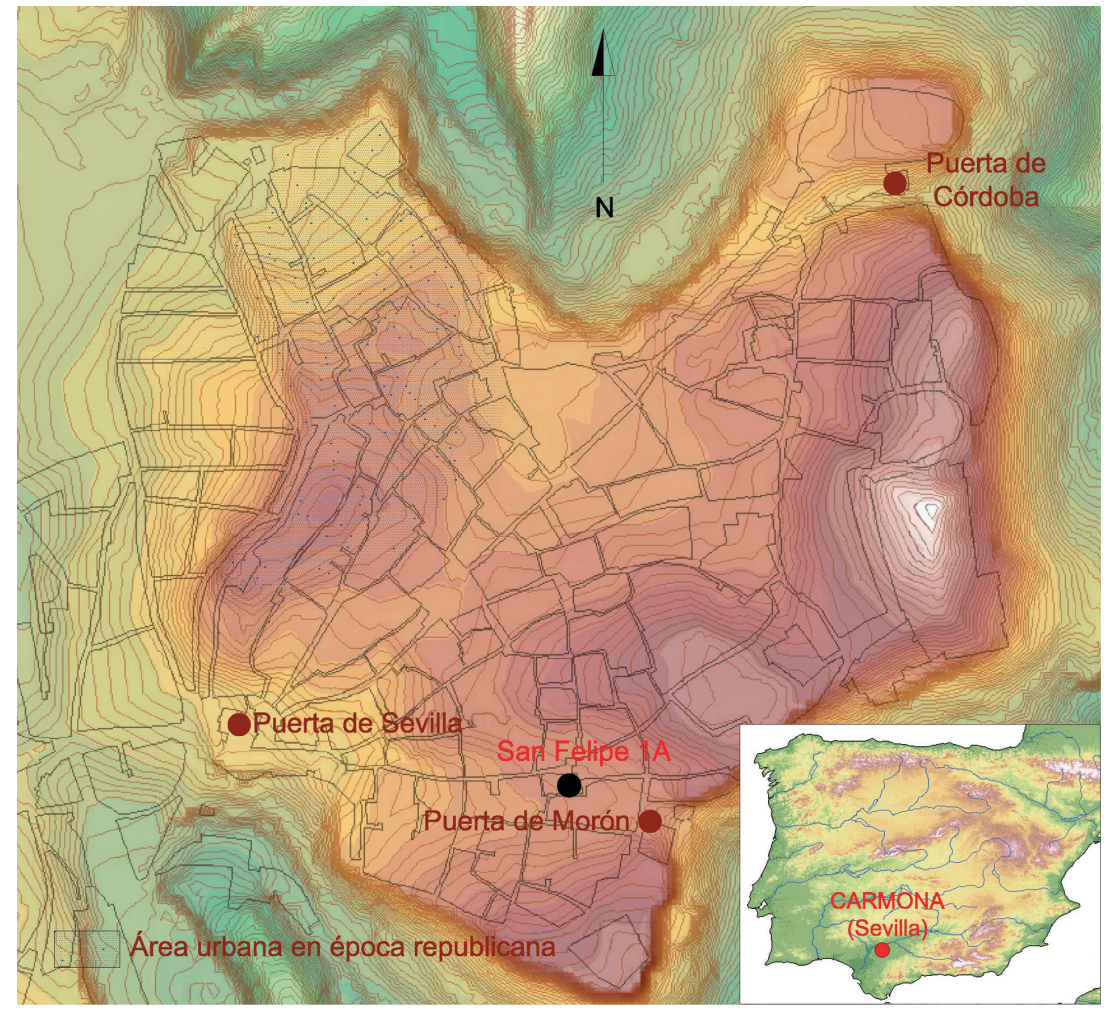

Fig. 1. Situación del santuario de la c/ San Felipe 1A en Carmona (Sevilla).
Plinio el Viejo alababa sus excepcionales cualidades para ser tallada y utilizada como sello porque no se le pega la cera, así como su amplio uso en época romana El mismo autor le da el nombre de sarda porque, dice, se encontró por primera vez en Sardes, capital de la antigua Lidia ${ }^{6}$.

El entalle presenta superficie plana en el anverso y el reverso es plano con contorno oval 7 . Mide $19 \times 14,3 \times 2 \mathrm{~mm}$ y su estado de conservación es óptimo, hasta el punto de hacer innecesario cualquier tratamiento de restauración o conservación. Tiene las caras anterior y posterior pulidas y un motivo grabado en hueco con gran precisión que

5 Plinio, Nat. Hist. 37, 21 y 31.

6 Otros autores relacionan el término con Cerdeña o con el griego бápł (carne), de donde derivan sinónimos de cornalina, como carnerina o carnelina (Casal, 1990: vol I, p. 35). Similar a la cornalina es el sardo que generalmente es más duro y tiene un color castaño oscuro, casi pardo, lo que provoca que la diferencia entre ambos no esté clara en muchas ocasiones, llevando a utilizar los dos nombres indistintamente.

7 Sección tipo p1 de Guiraud (1988: 29-31). ocupa un campo de 12,8 x 8,6 mm encuadrado en el óvalo (Fig. 4, n. ${ }^{\text {os }} 1-2$ ). Es una figura masculina alada de 12,4 $\mathrm{mm}$ de altura, con aspecto de adolescente o adulto joven, bien proporcionada y de estilo clásico ${ }^{8}$. Está de pie, desnuda y con los pies descalzos sobre la línea de suelo, cargando el peso del cuerpo sobre la pierna izquierda y con la derecha flexionada hacia detrás 9 . Gira ligeramente hacia su izquierda el tronco, quedando de perfil las alas y la cabeza en la misma dirección. Lleva el cabello peinado hacia atrás, recogido en la nuca con una especie de moño, y sostiene con ambas manos una antorcha larga cruzada en diagonal por delante del cuerpo -la derecha cerrada agarrando el mango y la izquierda abierta sólo sosteniéndolo-. La antorcha está encendida y flamea ${ }^{10}$.

8 Clásico modelado en la clasificación de Guiraud (1988: 48-50).

9 Seguimos el criterio de los especialistas describiendo el motivo según se observaría en la impronta del grabado (Guiraud, 1988: 84).

10 El mango de la antorcha mide $8,4 \mathrm{~mm}$. 


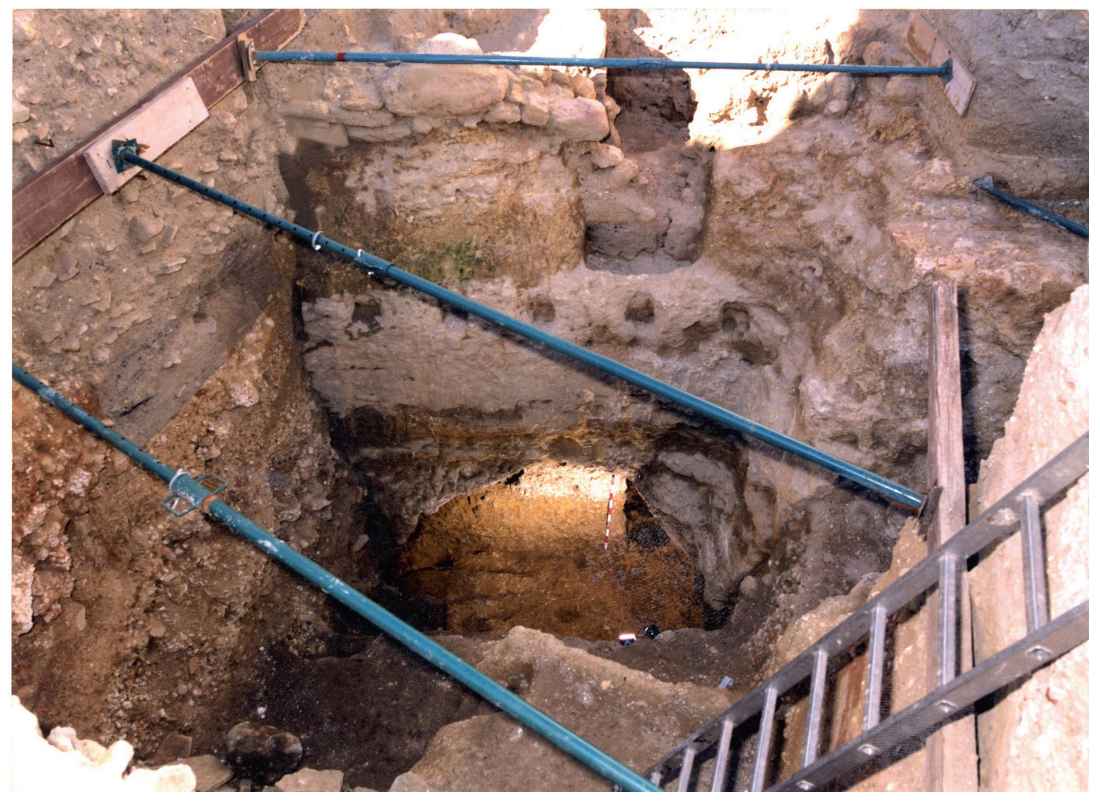

FIG. 2. Vista parcial del complejo rupestre de la c/ San Felipe en Carmona con la sala A al fondo.

Por sus características y atributos esta figura alada puede ser identificada como Eros/Cupido, cuya iconografía es bien conocida y está ampliamente representada en el mundo grecorromano. Eros, que no pertenecía originalmente al panteón romano, llega a Roma en época helenística -quizás antes- ${ }^{11}$, donde toma el nombre de Amor o Cupido ${ }^{12}$. Herencia de ese periodo histórico es también su imagen más extendida, la de un niño juguetón e irresponsa$b^{13}{ }^{13}$. Sin embargo, en el arte griego prehelenístico Eros fue representado como un joven o un adolescente bien parecido y no necesariamente alado. Este aspecto no infantil es el que muestra la figura del entalle de Carmona.

11 Blanc et al. (1987: 300) sitúan su llegada hacia mediados del s. IV a. C. y Elvira (2008: 248) en el s. v a. C.

12 Sobre el culto de Eros en Grecia y su desarrollo mitológico hay una amplia bibliografía; $c f$., entre otros, Fasce (1977); Hermary et al. (1986) y Breitenberger (2007: 137 y ss.). Respecto a Amor/Cupido cf. Blanc y Gury (1986).

13 "... In the Hellenistic period, as the idea of romantic love came increasingly to the fore in literature, Eros came to be imagined above all as a capricious and playful child-god" (Hard, 2004: 196). Sobre la figura del Eros putto remitimos a la completa monografía de Stuveras (1969).
Eros es un ser ambiguo y polimorfo, con una personalidad compleja y multifuncional ${ }^{14}$. El arte antiguo lo representa como figura en solitario, acompañando a Afrodita/Venus a la que algunas fuentes lo asocian en relación materno-filial ${ }^{15} \mathrm{o}$ en escenas en las que participan también otros dioses. Siempre fue una fuerza poderosa en el mundo antiguo. Safo de Lesbos, en el s. VI a. C., lo retrata sacudiendo su corazón "como el viento sobre los árboles al bajar por el monte"16. La poetisa le define como "el que afloja los miembros" 17 y, por primera vez en la literatura, le califica de "dulciamargo" 18 . Siglos después, y ya bajo la apariencia de un niño ciego alado, los poetas latinos lo describen una y otra vez como un ser caprichoso y despiadado, portador de desgracias para los hombres. Son muchos los pasajes en los que Cupido es objeto de reproches por parte, sobre todo, de los poetas elegíacos, pasajes que reflejan el topos del amor como tormento. Valgan como ejemplo dos versos de Propercio, eternamente consumido por su amor por Cintia: "Aquel dios enemista parientes, separa amigos / y a los bien concordes los llama a las funestas armas" ${ }^{19}$. O estos otros extraídos de la

14 Precisamente la complejidad del personaje de Eros o Amor es para Blanc et al. (1987) el principal problema que plantea su estudio iconográfico.

15 La idea aparece por primera vez en un fragmento de Simónides, quien lo describe como el hijo que la diosa dió a Ares (Hard, 2004: 196). La complejidad en torno a la identidad de Eros/Cupido se refleja en la variedad de genealogías que entretejen las distintas versiones sobre su origen (Hermary et al., 1986: 850-851; Blanc y Gury, 1986: 952-953; Breitenbreg, 2007: 137-138).

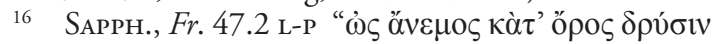
$\dot{\varepsilon} \mu \pi \varepsilon \dot{\varepsilon} \tau \omega v^{\prime \prime}$.

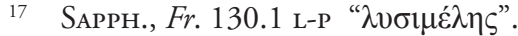

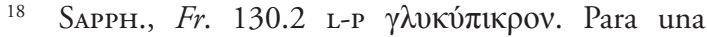
visión más completa de Eros en la épica y lírica griegas $c f$. Breitemberg (2007: 144-153).

19 Prop., 4. 34. 5-6: “... polluit ille deus cognatos, solvit amicos, / et bene concordis tristia ad arma vocat". 

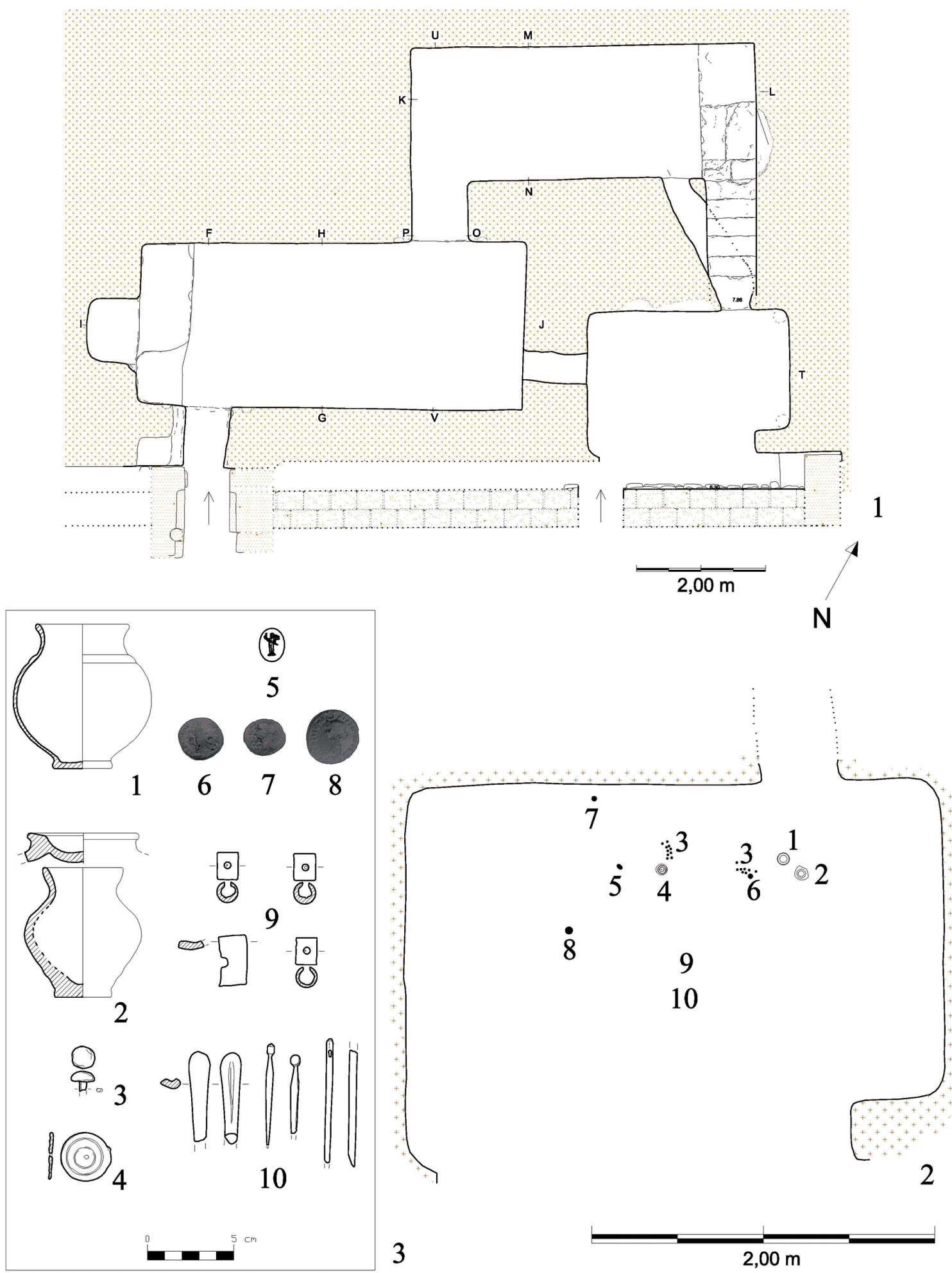

Fig. 3. Santuario de la c/ San Felipe en Carmona: 1) planta general; 2) detalle de la sala A; 3) material recuperado en ella. 

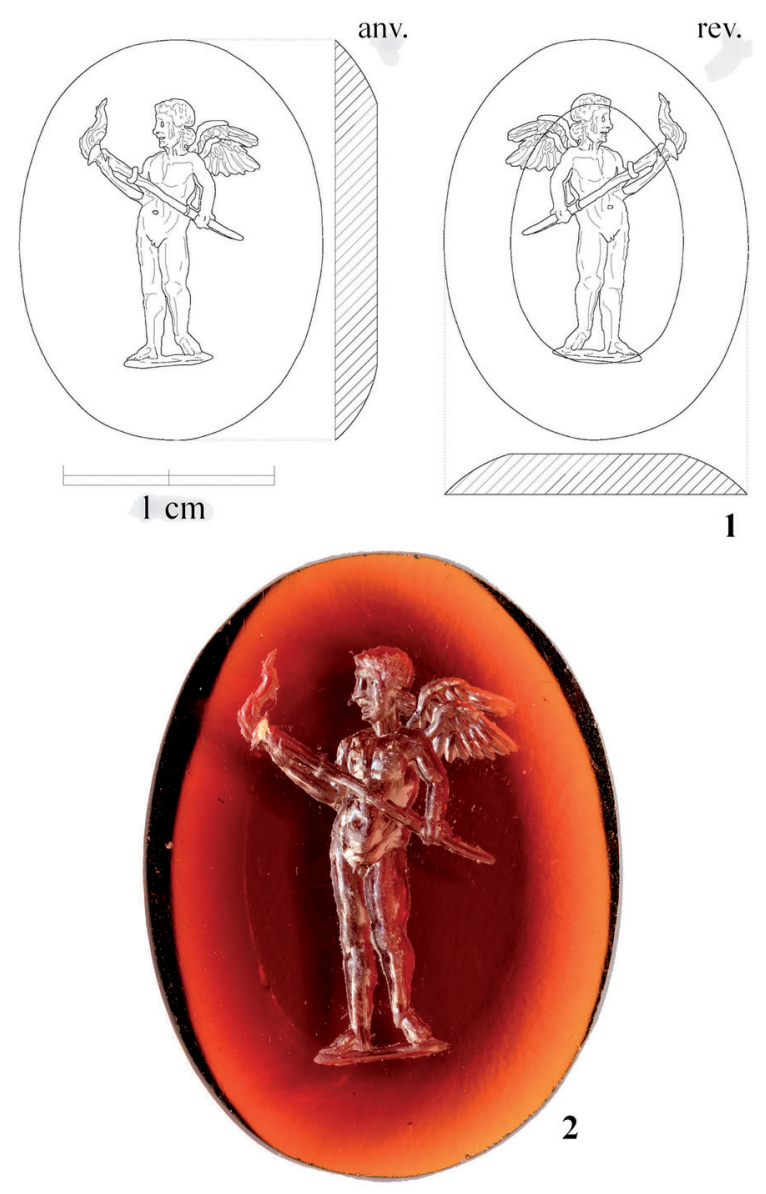

Fig. 4. Entalle con Eros/Cupido hallado en la c/ San Felipe en Carmona (dibujo: J. M. Román; fotog: N. F. Marqués).

desgarradora narración del episodio de Ariadna en Naxos de Catulo: “'Ay!, desgraciado, que agitas pasiones con corazón despiadado, / divino niño, que mezclas las alegrías con las penas de los hombres"20.

Por otro lado, de todos es conocida la imagen de Eros/Cupido inspirando amor al lanzar sus flechas directas al corazón de su víctima. En este sentido es interesante una elegía de Propercio en la que se entrelazan la visión destructora del pequeño dios con el poder dañino que portan sus flechas: "Bien armada está su mano con ganchudas saetas / y una faretra cretense cuelga de sus dos hombros: / y nos hiere antes de que, ilusos, vemos al enemigo, / y nadie sale sano

20 Catul, 64. 94-95: "Heu, misere exagitans immiti corde furores, I sancte puer, curis hominum qui gaudia misces". de esa herida" ${ }^{21}$. Además de sus flechas, Eros/AmorCupido suele portar casi con la misma frecuencia una antorcha que también utiliza como arma y que es, quizás, menos familiar para nosotros. Así se lamentaba Ovidio: “¿Por qué tu antorcha abrasa, por qué tu arco hiere a los amigos?”22, y requería Tibulo: "Pero deja las flechas y coloca, te lo ruego, tus ardientes antorchas lejos de aquín' 23 . Y es que la pasión siempre se asoció con el fuego, el fuego del amor, igual que se asocia hoy en día. En la literatura grecolatina encontramos innumerables alusiones a Eros/Cupido representando el fuego y la pasión cuando lleva una antorcha encendida, así como al tormento al que somete a los mortales usando esta misma antorcha. El poeta griego Mosco de Siracusa, en el s. II a. C., en un poema titulado Eros fugitivo presenta a Afrodita llamando en voz alta a su hijo y describiéndolo para quienquiera que lo encuentre: "Ese niño está marcado con señales numerosas y le reconocerías entre veinte más ... Todo lo que tiene es terrible, pero más que todo, su pequeña antorcha, que quema al propio Helios"24. Un siglo después, Meleagro de Gádara dedica un encantador poema a Fanio, cuyo nombre en griego significa, precisamente, 'lucecita' o 'pequeńa antorcha': "He intentado escapar de Amor, pero él, encendiendo una pequeña antorcha de las ascuas, me encontró escondido [...] y tomando un poquito de fuego me lo tiró en secreto. Y desde entonces las llamas surgieron en torno a mí por todas partes. Oh Fanio, pequeña niña que prendió en mi corazón un gran fuego" 25 .

Por su propia naturaleza, la antorcha es fuente de luz y puede utilizarse sencillamente para alumbrar el camino, en sentido real o metafórico. Así,

21 Prop., 2. 12. 9-12: “... et merito hamatis manus est armata sagittis / et pharetra ex umero Cnosia utroque iacet: I ante ferit quoniam tuti quam cernimus hostem, I nec quisquam ex illo vulnere sanus abit".

${ }_{22}$ Ov., Am. 2. 9. 5: “... cur tua fax urit, figit tuus arcus amicos?".

23 Тів., 2.1.81-82 “... sed pone sagittas / et procul ardentes hinc precor abde faces".

24 Mosco, Eros fugitivo vv. 6-23: “"̌ $\sigma \tau 1 ~ \delta$ ' ó $\pi \alpha \tilde{\mathrm{i} \zeta}$

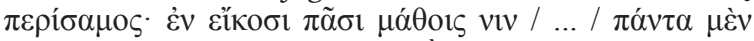

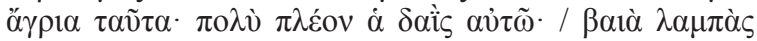

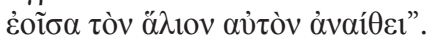

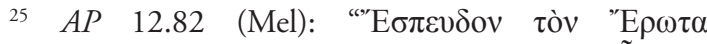

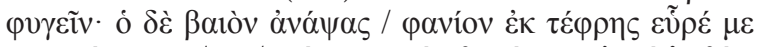

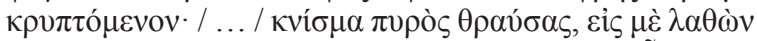

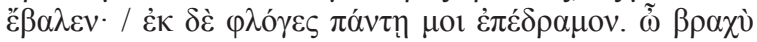

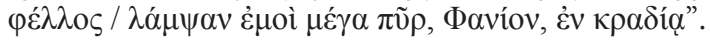


Eros no siempre se vale de ella para atormentar a los mortales con su fuego. Con la luz que esta produce el dios también guía el corazón del amante ${ }^{26}$. $\mathrm{La}$ antorcha es igualmente símbolo de la vida, por el poder regenerador y purificador del fuego, y de la muerte, como expresión de la vida que se extingue $^{27}$. De ahí que este instrumento sea, en determinados contextos, un accesorio cultual -no solo de Eros, sino también de otros dioses- y que se asocie igualmente con el fuego nupcial, la fiesta y el banquete $^{28}$. Por eso, las antorchas eran una parte esencial del ritual que tenía lugar en la celebración de las bodas. $\mathrm{Y}$ en este contexto Eros se confunde a veces con Himeneo, el cual es representado en el mundo clásico con aspecto y atributos casi idénticos a los de Cupido ${ }^{29}$.

Arco, flechas y antorchas son atributos bien documentados en las representaciones artísticas de Eros/Cupido, pero no los únicos. La personalidad del dios que nos transmiten las diferentes fuentes iconográficas greco-romanas -escultura y pintura,

26 Así, Propercio, en una noche en la que se dispone a ir a ver a su amada, dice "Amor mismo blande por delante las encendidas antorchas" (3.16.16 "ipse Amor accensas praecutit ante faces"). También Meleagro, recién llegado de un viaje por mar, cuenta cómo "Amor me arrastra a la fuerza, y como si llevara una antorcha delante de mí, me hace ver el encanto de un muchacho" (AP 12.84.3-4: "Ě $\lambda \kappa \varepsilon 1$

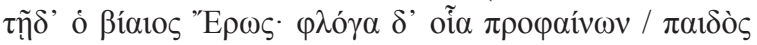

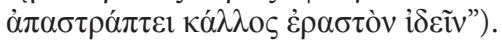

27 La iconografía más repetida representa a Eros/ Cupido dormido apoyado sobre una antorcha invertida donde el sueńo y la ausencia de llama son imagen de la muerte ( $c f$. Elvira, 2008: 249; también el capítulo de Stuveras [1969: 33-40] sobre el putto funerario). Hay autores que en estos casos prefieren hablar de 'genio funerario' para sortear el problema de la identificación de este con un dios al que las fuentes escritas no asocian nunca con el mundo de ultratumba (Blanc y Gury, 1986: 1047). Otros prefieren identificarlo con Hipno o con Tánato, ambos caracterizados frecuentemente con alas y ligados también al contexto funerario (Elvira, 2008: 249).

28 De donde Eros aparece frecuentemente vinculado a la esfera dionisíaca ( $c f$. Stuveras, 1969: 13-31). Anacreonte, en el s. vi a. C., ofrece una plegaria a Dioniso, que juega con "Amor, el que somete [...] y la radiante Afrodita" (Fr. 12.1-3

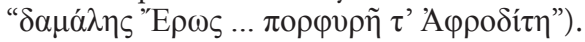

29 Dioscórides, a finales del s. III a. C., habla de "Himen, Himeneo, sujetando su brillante antorcha" (AP, 7.407.5: “Y "Y Sobre este problema, $c f$. también Stuveras (1969: 119-120) y Linant de Bellefonds (1991). glíptica, terracotas y decoraciones sobre vasos cerámicos- es mucho más rica que la imagen tópica de la producción literaria. Este otro ser de personalidad plural “... n’est pas seulement la divinité des amours mais celle aussi des amitiés, des bonnes ententes, de l'armonie entre les êtres y dans les familles" (Cassimatis, 2014: 61). Sin embargo, el significado preciso de las imágenes a veces se nos escapa, como ocurre con algunas representaciones sobre vasos de figuras rojas en las que Eros sostiene, precisamente, una caja entreabierta cuyo interior observa con atención (Hermary et al., 1986: n. ${ }^{\text {os }} 435$ y 557; Cassimatis, 2014: 513 y fig. 13). El problema de la identificación de Eros/Cupido, cuando no aparece ligado a un contexto claramente reconocible o a la esfera de Afrodita/Venus, lleva a menudo a los investigadores a hablar de 'genio alado' si su morfología es la de un adolescente o de putto o 'amorcillo' si se trata de un niño ( $c f$. Blanc et al., 1987: 298-300). De esta forma, se hace alusión al parecido de la figura en cuestión con el hijo de la diosa, pero se evita tomar partido sobre la identidad real del personaje y su función.

Eros/Amor-Cupido es la figura divina mejor representada en la glíptica de época romana ( $c f$. Guiraud, 1988: fig. 22), pero la iconografía del entalle de Carmona con la divinidad sosteniendo con ambas manos una gran antorcha cruzada por delante del cuerpo no es muy frecuente. La consulta de catálogos de importantes colecciones de glíptica españolas $^{30}$ y extranjeras ${ }^{31}$ ha resultado infructuosa y sólo hemos encontrado un paralelo casi exacto en un entalle de jaspe conservado en el Museo Kestner de Hannover (Schlüter et al., 1975: 272, fig. 1470). Es de fecha posterior -ss. II-III d. C.- y en él aparece una figura masculina alada, identificada con Cupido - cf. también Blanc y Gury, 1986: n. ${ }^{\circ}$ 177-, en una pose prácticamente idéntica a la del ejemplar de Carmona y con una larga antorcha encendida sujeta con las dos manos, aunque su calidad técnica y artística es menor y el personaje lleva

30 Casal García (1990) y López de la Orden (1990).

31 Entre otros Sena (1966 y 1978), Boardmann (1968), Richter (1971 y 2006), Zwierlein-Diehl (19731991 y 2007), Gramatopol (1974), Walters (1976), Henig (1978), Maaskant-Kleibrink (1978), Vollenwider (1979), Guiraud (1988), Pannuti (1983 y 1994), Tamma (1991), Platz-Horster (1994), Mandrioli (1987), Spier (1992), Krug (1995), Gersztelyi (2000) y Weiss (2007). 
el pelo corto (Fig. 5, n. ${ }^{\circ}$ 1). El cabello recogido en un moño alto tiene el Eros grabado con técnica de entalle en el chatón de un anillo de oro del Cabinet des Médailles de la Biblioteca Nacional de Francia, pero la antorcha es algo más corta y la sostiene con una sola $\operatorname{mano}^{32}$. Esta pieza se fecha entre el último cuarto del s. IV y el primero del s. III a. C.

Por el contrario, la iconografía de Eros/Cupido sosteniendo con ambas manos una antorcha de largo mango la encontramos en otras manifestaciones artísticas del mundo romano. Las pinturas murales de Pompeya, por ejemplo, nos ofrecen paralelos en los que el dios, sin embargo, se representa con un aspecto más infantil siguiendo los cánones estéticos de la época y viste clámide, aunque la capa no cubre su desnudez (Fig. 5, n. ${ }^{\circ}$ 2). De la misma forma se muestra también en los relieves de los sarcófagos romanos, donde se acompańa de otros seres alados (Fig. 5, n.o 3). Por último, el omnipresente dios aparece en el reverso de diferentes tipos de monedas provinciales de época romana. Lo vemos en solitario o junto a otros Erotes, con Psyche o acompañando a Afrodita o a otra deidad, pero la iconografía de Eros con antorcha cruzada delante del cuerpo es común sobre todo en acuñaciones de Aphrodisias, ciudad de la región de Caria que gozó del patronazgo de Afrodita, como su propio nombre indica. Están fechadas hacia 178-180 d. C. y en ellas esta deidad aparece en una pose muy parecida a la de nuestro entalle, pero con las alas desplegadas en visión frontal, la cabeza de perfil hacia la derecha o hacia la izquierda, totalmente desnudo o con clámide y, en algún caso al menos, con el pelo recogido en un moño sobre la nuca o con una coleta ${ }^{33}$ (Fig. 5, n. ${ }^{\circ}$ ).

32 Cabinet des Médailles, BnF, n.o inv. 56.497, chab. 2630, inv. mon. or n. ${ }^{\circ} 497$. (http://medaillesetantiques. bnf.fr/ws/catalogue/app/collection; acceso 14-12-2014). Asimismo existe parecido entre esta imagen de Eros y algunas figurillas de bronce con antorcha encendida en una mano, si bien el tipo iconográfico no es exactamente el mismo representado en el entalle que estudiamos. Una de ellas está en París, en el Cabinet des Médailles ( $c f$. LIMC III, "Eros in peripheria orientali" n. ${ }^{0} 17$. También on-line en la base de datos del LIMC, http://www.limc-france. fr, con n. ${ }^{\circ}$ de referencia 14197); la segunda pertenece al Museo de Harvard ( $c f$. LIMC III, "Eros" 387 o http://www. harvardartmuseums.org/art/303784).

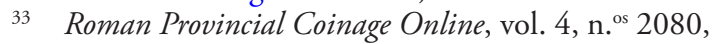
2081 y 2235 (http://rpc.ashmus.ox.ac.uk/coins/; acceso 17-12-2014). Todas ellas corresponden al tipo 119 de MacDonald (1992).

(C) Universidad de Salamanca

\section{Conclusiones}

A la singularidad del motivo grabado, que reproduce un modelo poco común en la glíptica romana, y a su calidad técnica y artística, el entalle que estudiamos en estas páginas suma el interés de haber sido hallado en un contexto arqueológico bien documentado, fechado por el registro cerámico en tiempos del emperador Vespasiano o algo posterior. En realidad, esas fechas son las de la amortización de la caja y su probable contenido en la sala más pequeña del complejo cultual rupestre descubierto en Carmona y suponen un terminus ante quem para la producción y uso de la pieza, aunque los dos hechos pudieron estar próximos en el tiempo. La datación del tercer cuarto del s. I no se contradice con la que corresponde al estilo artístico clásico de la imagen grabada, de moda a lo largo del s. I y principios del s. II d. C. (Guiraud, 1988: 48-50).

La caja y su contenido, junto con los dos pequeños vasos de cerámica depositados sobre el suelo de la estancia, se interpretan como posibles ofrendas realizadas durante las ceremonias con las que se puso fin a la actividad del santuario. Los objetos óseos para el arreglo personal y la aguja de coser confieren un carácter femenino a ese gesto cultual que incluyó también el entalle con representación de Eros/ Cupido tallado en cornalina, en el que coinciden la piedra más apreciada y el dios más solicitado por los clientes de los gemmarii romanos (Giraud, 1988: 26, figs. 7 y 22). Testimonios de su popularidad en Carmona son también otro entalle hallado en una tumba todavía inédita, en este caso engastado en un anillo de hierro, con la imagen del dios tañendo la $\operatorname{lira}^{34}$, y un mosaico de fines del s. II o principios del s. III en el que navega en un barco de fantasía -un ánfora- impulsado a vela (Cartaya, 2001: 302$304)^{35}$, sin que falten los detalles dionisíacos que hablan de su relación con el dios del vino (Hermary et al., 1986: 941; Blanc y Gury, 1986: 1045).

Eros no fue sólo un dios de mujeres (Cassimatis, 2014: 526), pero sus amplias funciones lo hicieron indispensable en situaciones y problemas que afectaban a ese colectivo social: el paso de la pubertad a la edad núbil, el matrimonio, la fecundidad y los

\footnotetext{
34 Agradecemos la información a R. Lineros, director del Museo de la Ciudad de Carmona (Sevilla).

35 El motivo está documentado también en entalles (Guiraud, 1988: lám. xxıII, n.o 354).
} 
hijos. La representación frecuente de elementos de aseo y frascos de perfumes en las decoraciones vasculares expresan su reconocida competencia en la esfera de la seducción y la sexualidad. La presencia de esta compleja divinidad, una y múltiple (Cassimatis, 2014: 67), no resulta extraña en un santuario supuestamente consagrado a Mercurio, sin que ello signifique que se diera en él un culto compartido por ambos. De hecho, en el mundo grecoromano hay tan abundantes signos de la devoción privada a Eros/Cupido, como escasas son las evidencias arqueológicas de que se le dedicara culto oficial y reglado (Blanc y Gury, 1986: 1049; Cassimatis, 2014: 57, 70). Son muchas las afinidades que unían a esta pequeña divinidad con Hermes, el ascendente griego de Mercurio. Alguna fuente literaria los emparenta en relación paterno-filial ${ }^{36}$ y ambos compartían competencias y atributos, como la lira y el caduceo que Eros adoptó como propios (Hermary et al., 1986: n. ${ }^{\text {os }} 948$ 949). Hermes intervenía también en los dominios del amor (Otto, 1981: 134136) y junto a Afrodita y Eros formaba parte de las "divinidades que le susurran a la joven desposada las palabras que podrán acercarla a su esposo, los murmullos que les permitirán encontrarse" (KahnLyotard, 1996: 258; cf. también Siebert, 1990: 373). En este común ámbito de actuación cobra sentido la presencia en el santuario de un pequeño cofre con pertenencias femeninas, similar a los que sostiene Eros en algunas representaciones
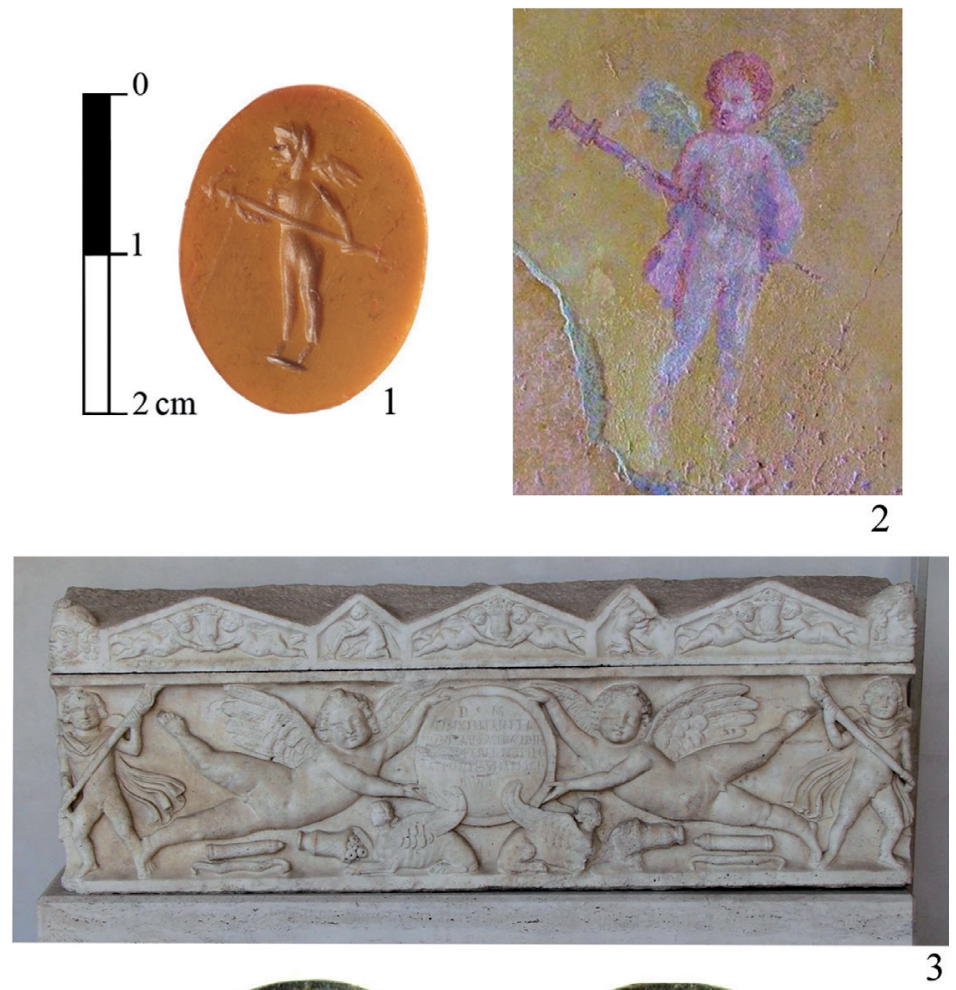
sobre cerámica de figuras rojas del s de Italia, entre mujeres que se acicalan, pa-
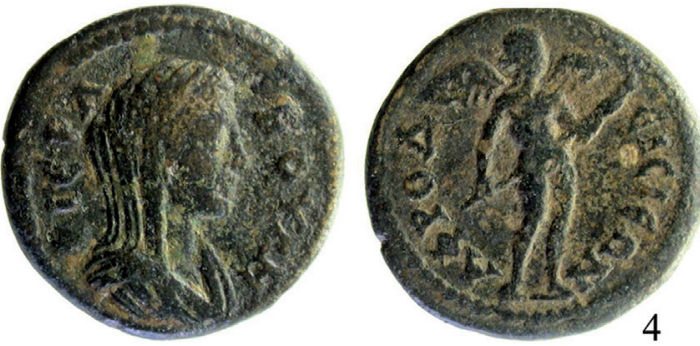

rejas jóvenes -hombre y mujer- o en ambientes de gineceo claramente alusivos a la preparación de la novia para las nupcias (Hermary et al., 1986: n. ${ }^{\text {os }}$ 557 y 651b). Como decíamos más atrás, la caja pudo quedar abandonada in situ, como pasó con piezas de una vajilla de mesa que estaban en buen

36 Cicerón. N. D. 3. 59. 1-3: "Venus prima Caelo et Die nata / [...] ex qua et / Mercurio Cupidinem secundum natum accepimus". uso (Belén et al., 2014a: 120-122), pero nos parece más probable que se depositara de forma intencional antes de clausurar el local. La ofrenda pudo realizarse durante los actos con los que se puso fin al complejo cultual carmonense, pero la arqueología no nos permite saber si se depositó en un ritual de paso o iniciación al matrimonio, si fue un exvoto propiciatorio de fertilidad o, simplemente, un devoto homenaje a la divinidad titular del santuario que poco después se abandonaría para siempre. 


\section{Fuentes}

Anacreonte. Iambi et elegi Graeci. West, M. L. (ed.) (1972). Oxford: Clarendon Press.

Catul. = Catullus. Goold, G. P. (ed.) (I983). London: Duckworth.

Dioscórides = AP. Epigrammata. Anthologia Palatina . Beckby, H. (ed.) (1966; 2. ${ }^{\mathrm{a}}$ ed.). Munich: Heimeran.

Meleagro = Meleager. Epigrammata. Anthologia Palatina . H. Becквy, H. (ed.) (1966, 2. a ed.). Munich: Heimeran.

Mosch = Moschus. Bucolici Graeci. Gow, A. S. F. (ed.) (1952). Oxford: Clarendon Press.

Ov. = Ovid in six volumes. Vol. 1: Heroides and Amores. With an English translation by Grant Showerman. Goold, G. P. (ed.) (1977). Loeb Classical Library, 41. Cambridge: Harvard University Press.

Plinio = Mayhoff, C. (ed.) (1897): C. Plini Secundi Naturalis Historiae Libri xxvir. Vol. 5. Leipzig: Teubner.

Prop. = Propertius, Elegies. Edited and translated by G. P. Goold (1990). Loeb Classical Library, 18. Cambridge: Harvard University Press.

SAPph. $=$ Sappho. Poetarum Lesbiorum fragmenta . Lobel, E. y Page, D. L. (eds.) (1955). Oxford: Clarendon Press.

Tів. = Albii Tibulli Aliorumque Carminum Libri Tres. Lenz, F. W. y Galinsky, G. K. (eds.) (1971). Leiden.

\section{Bibliografía}

Balsdon, J. P. D. V. (1962): Roman Women: Their History and Habits. London: Bodley Head.

Baratta, G. (2001): Il culto de Mercurio nella Penisola Iberica. Barcelona: Public. i Edic. Univ. Barcelona.

Belén, M.; Román, J. M. y VÁzquez Paz, J. (2014a): “Arquitectura religiosa en la Carmona antigua. El santuario de la calle San Felipe 1A”. En González, M.; CabALlos, A. y Ruiz, J. A. (eds.): Urbanismo, Arquitectura y Patrimonio en Carmona. Actas del IX Congreso de Historia de Carmona (Carmona, Sevilla, 2013). Sevilla: Univ. Sevilla, pp. 102-133.

Belén, M.; Román, J. M. y Vázquez Paz, J. (2014b): "Modelos clásicos para imágenes populares. Mercurio en una terracota de Carmona (Sevilla)". En In Amicitia. Miscel-lània d'estudis en homenatge a Jordi H. Fernández. Treballs del Museu Arqueològic d'Eivissa i Formentera, 72. Eivissa: Museu Arqueològic d'Eivissa, pp. 87-98.

Blanc, N. y Gury, F. (1986): “Amor, Cupido”. En Lexicon Iconographicum Mythologiae Classicae, III. 1. ZürichMunich-Düsseldorf: Artemis Verlag, pp. 952-1049.

Blanc, N.; Gury, F. y Lerede, H. (1987): "Les images d'Amor: une expérience d'informatisation", Revue Archéologique, pp. 297-334.

Boardman, J. (1968): Engraved gems: the Ionides Collection. Evanston-Illinois: Northwestern University Press.
Breitenberger, B. (2007): Aphrodite and Eros. The Development of Erotic Mythology in Early Greek Poetry and Cult. London: Routledge.

Cartaya, J. (2001): "Mosaicos romanos de Carmona”. En Caballos, A. (ed.): Carmona romana. Actas II Congreso de Historia de Carmona (Carmona, Sevilla, 1999). Carmona: Ayto. de Carmona, pp. 293-309.

Casal, R. (1990): Colección de Glíptica del Museo Arqueológico Nacional (Madrid). Serie de entalles romanos. Madrid: Ministerio de Educación, Cultura y Deporte.

Cassimatis, H. (2014): Éros dans la céramique à figures rouges italiote. Paris: De Boccard.

Elvira Barba, M. A. (2008): Arte y mito. Manual de Iconografía Clásica. Madrid: Sílex.

Fasce, S. (1977): Eros. La figura e il culto. Genova: Univ. di Genova.

Feugère, M. y Prévot, Ph. (2008): "Les matières dures animales (os, bois de cerf et ivoire) dans la vallée del'Hérault; production et consommation". En BERTRAND, I. (ed.): Le travail del'os, du bois de cerf et de la corne à l'époque romain: un artisanat en marge? Actes du colloque de Chauvigny (Chauvigny, 2005). Monographies Instrumentum, 34. Montagnac: Éditions Monique Mergoil, pp. 231-268. (https://hal.archives-ouvertes.fr/ halshs-00265987; acceso 16-02-2015).

Gesztelyi, T. (2000): Antike Gemmen im Ungarischen Nationalmuseum, Catalogi Museo Nationalis Hungarici. Serie Archaeologica, III. Budapest: Ungarisches Natio-nalmuseum.

Gramatopol, M. (1974): Les pierres gravées du cabinet numismatique de l'Académie Roumaine. Bruxelles: Latomus.

Guiraud, H. (1988): Intailles et camées de l'époque romaine en Gaule (Territoire français). 48e supplément à Gallia. Paris: CNRS.

Hard, R. (2004): The Routledge Handbook of Greek Mithology. London-New York: Routledge.

Henig, M. (1978): A Corpus of Roman engraved gemstones from British sites. Oxford: BAR.

Hermary, A.; Cassimatis, H. y Vollkommer, R. (1986): "Eros". En Lexicon Iconographicum Mythologiae Classicae III. 1. Zürich, Munich, Düsseldorf: Artemis Verlag, pp. $850-942$.

Khan-Lyotard, L. (1996): "Hermes". En Pórtulas, J.; Sola, M. (eds.) y Bonnefoy, I. (dir.): Diccionario de las mitologías y de las religiones de las sociedades tradicionales del mundo antiguo. Barcelona: Destino, pp. 256-267.

KRUG, A. (1995): Römische Gemmen im Rheinischen Landesmuseum Trier. Trier: Rheinisches Landesmuseum Trier.

Linant de Bellefonds, P. (1991): "Hymenaios: une iconographie contestée”. En KaHIL, L. y LinANT DE Bellefonds, P. (eds.): Religion, Mythologie, Iconographie. Actes colloque international (Rome, 1989). Mélanges de l'École Française de Rome, Antiquité 103-1. Roma: École Française de Rome, pp. 197-212. 
López de LA Orden, M.a D. (1990): La gliptica de la antigüedad en Andalucía. Cádiz: Univ. Cádiz.

Maaskant-Kleibrink, M. (1978): Catalogue of the Engraved Gems in the royal Coin Cabinet, The Hague: The Greek, Etruscan and Roman Collections. The Hague: Govt. Pub. Office.

Mandrioli, A. R. (1987): La collezione di gemme del Museo Civico Archeologico di Bologna. Casalecchio di Reno, Bologna: Grafis.

McDonald, D. (1992): The Coinage of Aphrodisias. London: Royal Numismatic Society.

Отто, W. F. (1981): Les dieux de la Grèce. La figure du divin au miroir de l'esprit grec. Paris: Payot.

Pannuti, U. (1983): Museo Archeologico Nazionale di Napoli. Catalogo della collezione glittica, vol. 1. Roma: Istituto Poligrafico e Zecca dello Stato.

Pannuti, U. (1994): Museo Archeologico Nazionale di Napoli. Catalogo della collezione glittica, vol. 2. Roma: Istituto Poligrafico e Zecca dello Stato.

Platz-Horster, G. (1984): Die antiken Gemmen im Rheinischen Landesmuseum Bonn. Köln-Bonn: Rheinland-Verlag.

Richter, G. M. A. (1971): Engraved gems of the Romans: A supplement to the history of Roman art. London: Phaidon.

Richter, G. M. A. (2006): Catalogue of engraved gems: Greek, Etruscan, and Roman. The Metropolitan Museum, New York. Roma: L'Erma di Bretschneider.

Rodríguez Casanova, I. (1999): "Consideraciones sobre la iconografía monetal de la ceca de Carmo: el Mercurio Africano". En Mora, G.; Sobral, R. M. y GarcíaBellido, M. ${ }^{a}$ P. (coords.): Rutas, ciudades y moneda en Hispania. Actas II Encuentro Peninsular de Numismática Antigua (Porto, 1997). Anejos Archivo Español de Arqueología, xx. Madrid: csic, pp. 333-340.
SChlüter, M.; Platz-Horster, G. y Zazoff, P. (1975): Antike Gemmen in deutschen Sammlungen, vol. 4: Kestner-Museums, Hannover; Museum für Kunst und Gewerbe, Hamburg. Wiesbaden: Prestel Verlag.

Sena Chiesa, G. (1966): Gemme del Museo Nazionale di Aquileia. Padova: Associazione Nazionale per Aquileia.

Sena Chiesa, G. (1978): Gemme di Luni. Archaeologica, 4. Roma: G. Bretschneider.

SieberT, G. (1990): "Hermes". En Lexicon Iconographicum Mythologiae Classicae I. Zürich: Artemis Verlag, pp. 285-387.

Spier, J. (1992): Ancient Gems and Finger Rings. Catalogue of the Collections. The J. Paul Getty Museum. Malibu, California: J. Paul Getty Museum (http:// d2aohiyo3d3idm.cloudfront.net/publications/virtuallibrary/0892362154.pdf; acceso 10-11-2014).

Stewart, S. (2007): Cosmetics and Perfumes in the Roman World. Gloucestershire: Tempus.

Stuveras, R. (1969): Le putto dans l'art romain. Col. Latomus, 99. Bruxelles.

Tамma, G. (1991): Le gemme del Museo Archeologico de Bari. Bari: Edipuglia.

Vollenwider, M. L. (1979): Catalogue raisonné des sceaux, cylindres, intailles et camées, vol. II. Mainz am Rhein: Philipp von Zabern.

Walters, H. B. (1976): Catalogue of the engraved gems and cameos, Greek, Etruscan and Roman, in the British Museum. London: The Trustees of the British Museum.

WeIss, C. (2007): Die antiken Gemmen der Samnlung Heinrich Dressel in der Antikensammlung Berlin. Würzburg: Ergon-Verlag.

Zwierlein-Diehl, E. (1973-1991): Die antiken Gemmen des kunsthistorisches Museums in Wien, 3 vols. München: Prestel.

Zwierlein-Diehl, E. (2007): Antike Gemmen und ihr Nachleben. Berlin-New York: Walter de Gruyter. 